\title{
A INSTITUIÇÃO DE ENSINO SUPERIOR COMO GERADORA DE INOVAÇÃO SOCIAL: UMA PROPOSTA DE ROADMAP PARA A TRANSFORMAÇÃO SOCIAL
}

\author{
THE HIGHER EDUCATION INSTITUTION AS A GENERATOR OF SOCIAL \\ INNOVATION: A ROADMAP PROPOSAL FOR SOCIAL TRANSFORMATION
}

\author{
Joyce Pinho Furlan \\ Bacharel em Administração \\ Faculdade de Tecnologia Termomecanica - FTT \\ São Bernardo do Campo, SP - Brasil \\ joycepinhofurlan@gmail.com \\ Bacharel em Administração \\ Faculdade de Tecnologia Termomecanica - FTT \\ São Bernardo do Campo, SP - Brasil \\ luccabrazile@gmail.com \\ Victor Brazile Beneton \\ Bacharel em Administração \\ Faculdade de Tecnologia Termomecanica - FTT \\ São Bernardo do Campo, SP - Brasil \\ victor.beneton@gmail.com \\ Leandro Rodrigues da Silva \\ Mestre em Administração - Gestão da Inovação \\ Faculdade de Tecnologia Termomecanica - FTT \\ São Bernardo do Campo, SP - Brasil. \\ Leandros_r@hotmail.com
}

Resumo: O processo de transformação social se manifesta dentro de uma universidade inserida no contexto da Segunda Revolução Acadêmica, que assume a condição adicional das contribuições provenientes da Primeira Revolução Acadêmica. O objetivo deste trabalho de pesquisa é analisar como o processo de inovação social acontece dentro de uma Instituição de Ensino Superior (IES) e propor um roadmap facilitador para promover a transformação social, por intermédio da implementação de atividades de extensão universitária. A metodologia é caracterizada pela pesquisa qualitativaquantitativa de caráter exploratório, por intermédio de estudo de caso com a realização de entrevistas com gestores, grupo focal e aplicação de questionário com a comunidade escolar, executando uma análise de conteúdo apoiada em documentos disponíveis em plataformas acadêmicas. Os resultados mostram o potencial de influência social que uma IES pode exercer em torno de sua região, adquirindo um importante papel no processo de formação dos alunos e transformação da comunidade local. Assim, esse trabalho contribui ao lançar um roadmap capaz de ser um ferramental no estímulo da inovação social dentro de IES, possibilitando a gestão de atividades de extensão universitária, bem como a proposição de uma nova forma de aplicar o conhecimento em benefício comum, ao estimular o empreendedorismo e inovação social em prol do desenvolvimento econômico e social.

Palavras-chave: Inovação social. Instituição de Ensino Superior. Roadmap. Extensão universitária. Quádrupla hélice.

Abstract: The process of social transformation is manifested within a university inserted in the context of the Second Academic Revolution, which assumes the additional condition of contributions from the First Academic Revolution. The objective of this research work is to analyze how the process of social innovation happens within a Higher Education Institution (HEI) and to propose a facilitating roadmap to promote social transformation, through the implementation of university extension activities. The methodology is characterized by qualitative-quantitative research of an exploratory nature, through a case study with interviews with managers, a focus group and the application of a questionnaire with the school community, performing a content analysis supported by documents available on academic platforms. The results show the potential for social influence that an HEI can exert around its region, acquiring an important role in the process of training students and transforming the local community. Thus, this work contributes by launching a roadmap capable of being a tool in stimulating social innovation within HEIs, enabling the management of university extension activities, as well as proposing a new way of applying knowledge for common benefit, by stimulating entrepreneurship and social innovation in favor of economic and social development.

Keywords: Social innovation. Higher educational institution. Roadmap. University extension. Fourth helix.

\section{$\underline{\text { Cite como }}$}

American Psychological Association (APA)

FURLAN, J. P., Beneton, L. B., Beneton, V. B., \& Silva, L. R. (2021, jul./dez.). A instituição de ensino superior como geradora de inovação social: uma proposta de ROADMAP para a transformação social. Revista Inovação, Projetos e Tecnologias - IPTEC, São Paulo, 9(2), 216-238 https://doi.org/10.5585/iptec.v9i2.19961 


\section{Introdução}

Um dos números da crise gerada pela pandemia de 2020 é a taxa de desemprego que, segundo o Instituto Brasileiro de Geografia e Pesquisa (IBGE, 2020), atingiu 12 milhões e 700 mil brasileiros e acentuou a falta de postos de trabalho e a necessidade de mudanças de comportamento. Além de desemprego, a população também acaba sofrendo com problemas desencadeados pela falta de renda como, por exemplo, o aumento da fome, a falta de acesso à infraestrutura de água, luz e moradia, sobretudo com a desinformação sobre a pandemia e as condições de acesso para recolocação no mercado de trabalho.

A fim de promover mudanças que tragam benefício social para as pessoas que perderam seus empregos ou se encontram em situação de vulnerabilidade social, a Instituição Ensino Superior (IES) pode exercer um relevante papel nesse processo, pois além do ensino, pesquisa e democratização do conhecimento, essas instituições estão inseridas no contexto da Segunda Revolução Acadêmica. Segundo Etzkowitz (1998), esta revolução é caracterizada pela promoção de ações de extensão universitária. Para Costa (2018), essa transição proporciona meios de inovar o processo de formação e representa o ensino "empresarial" e "social", que exercem papel chave no entendimento do processo de inovação transformadora e na relação da Quarta Hélice (Carayannis, 2010), conceitos provenientes de teorias como o triângulo de Sábato (Sábato \& Botana, 1968).

Diante de tal contexto, o objetivo geral deste trabalho é analisar como o processo de inovação social acontece dentro de uma Instituição de Ensino Superior e propor um roadmap facilitador para promover a transformação social, por intermédio da implementação de atividades de extensão universitária. Como objetivos específicos, a pesquisa visa compreender o papel dos atores envolvidos nesse processo e adquirir uma visão administrativa dos projetos sociais.

O estudo de caso analisado é uma IES localizada na região do Grande ABC, que iniciou suas atividades no ano de 2003. A IES é de caráter privado e totalmente gratuito, comprometida com a transformação social através da educação. Hoje, conta com quatro cursos de Bacharelado - sendo todos estes credenciados pelo Ministério da Educação (MEC). A instituição também possui dois cursos de pós-graduação. A IES foi escolhida devido ao seu papel ativo na inovação social com três programas vigentes, sendo: programa para aconselhamento e ajuda ao iniciar a carreira no mercado de trabalho, programa de suporte e plantão de dúvidas referente à realização do imposto de renda com foco na comunidade local e um programa em parceria 
faculdade-alunos para atender às demandas de ONGs, sendo este último o objeto de pesquisa deste trabalho.

O referencial teórico é base para o levantamento de dados, pelo qual buscou-se a compreensão de como o processo de inovação social toma espaço e quem são os atores envolvidos (alunos da IES, direção, coordenação, professores) com a finalidade de propor um modelo a ser tomado como referência e revelar o protagonismo da academia.

Portanto, o trabalho compreende a IES como responsável por estimular ações empreendedoras e inovadoras para assim atingir uma transformação econômica e social ao utilizar ferramentas que fomentem a inovação. Este papel integra a academia à sociedade civil, acordando com o momento de Segunda Revolução Acadêmica e Quádrupla Hélice e, como resultado, propõe um roadmap para implantação de projetos de inovação social em IES, sendo referência no processo de promoção de inovação social através da academia.

A estrutura deste artigo tecnológico parte do desenvolvimento da ideia na introdução e, no decorrer do referencial teórico, explora os conceitos e teorias de Quádrupla Hélice e Segunda Revolução Acadêmica para fundamentar o estudo de caso. A metodologia atribui caráter científico ao estipular práticas de pesquisa para maior credibilidade. No capítulo de resultados e discussões, são discutidos os dados recolhidos em prol de formar informações para compreender a relação dos atores envolvidos, propondo um roadmap referência ao agregar a inovação no processo. E, por fim, são apresentadas as considerações finais, as limitações da pesquisa e sugestão de trabalhos futuros. Essas reflexões podem auxiliar futuras pesquisas no campo de desenvolvimento em questão e fortalecer novas visões que complementem os estudos sobre inovação social.

\section{Referencial teórico}

\subsection{Revolução acadêmica}

A IES revela-se como campo de estudo do trabalho de pesquisa, portanto é fundamental compreender o seu desenvolvimento durante a história e como sua atuação passou por mudanças, sendo responsável por promover o ensino até contribuir, de forma ativa, economicamente e socialmente para a comunidade (Carayannis \& Campbell, 2015). Etzkowitz (1998) estabelece uma linha do tempo para esse processo e aponta que, em meados do século $\mathrm{XI}$, as universidades promoviam o ensino em prol de compartilhar conhecimento, entretanto os constantes acontecimentos históricos, como guerras e revoluções industriais, motivaram um novo olhar para a academia e atribuíram novas responsabilidades para a IES. 
Em meados do século XVII, a Primeira Revolução Acadêmica ocorreu nos Estados Unidos, a fim de legitimar a pesquisa como uma missão das universidades. Desta forma, promove uma maior amplitude na visão e desenvolvendo o papel de geradora de conhecimento e tecnologia (Zhao et al., 2017; Etzkowitz, 1998).

Para Etzkowitz (1998), a Segunda Revolução Acadêmica tem origem na segunda metade do século XX. Almeida e Cruz (2010) complementam a ideia ao entender tal momento cronológico como maior engajamento das organizações para com questões econômicas e sociais, capazes de propiciar condições de incentivo à inovação e, consequentemente, encorajar o espírito empreendedor presente na teoria schumpeteriana.

Dessa forma, a Segunda Revolução Acadêmica contribui com o caráter transformador da IES, uma vez que sua fundamental contribuição para a sociedade pode ser encontrada na transferência de conhecimento e tecnologia, proporcionando meios de inovar e empreender. Tal momento representa a transição para o ensino "empresarial", no qual a faculdade passa a exercer o papel chave no entendimento do processo de inovação transformadora (Costa, 2018).

As universidades tiveram seu início em meados do século XI, e, com as revoluções acadêmicas observadas a partir do século XVII, foram moldando-se como pólos de desenvolvimento científico, econômico e social, contextualizando o papel de indutor no processo de inovação social. A figura 1 ilustra linearmente o processo evolutivo das revoluções acadêmicas:

\section{Figura 1.}

\section{Revoluções Acadêmicas}

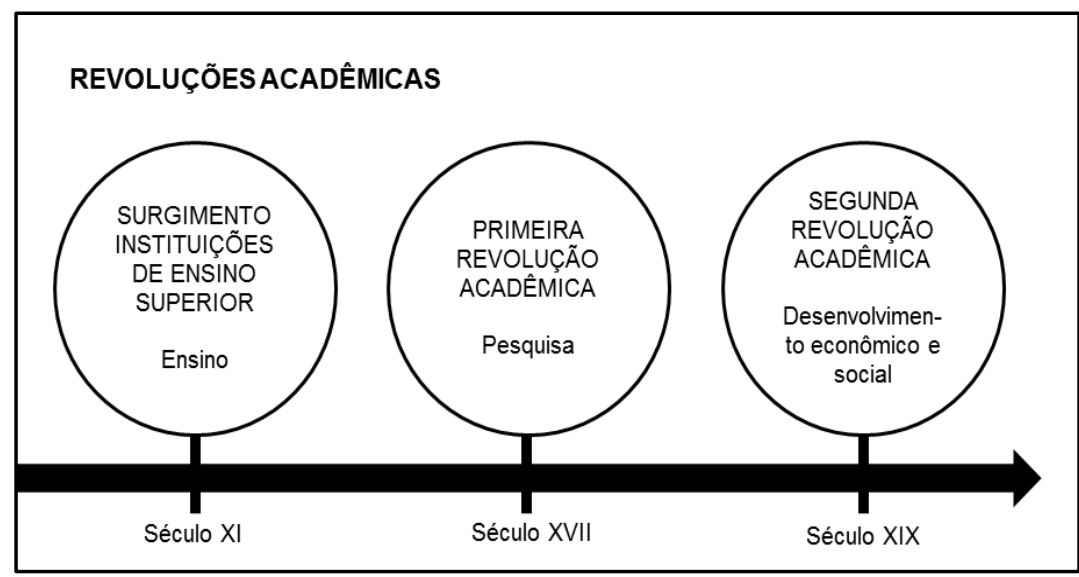

Fonte: Desenvolvida pelos autores (2021). 
Portanto, a IES passa a ser reconhecida como universidade empreendedora ou inovadora e serve a sociedade com ideias voltadas para mudança social e desenvolvimento econômico, deixando de difundir exclusivamente as funções de ensino e pesquisa e propiciando inovação social como uma de suas diretrizes (Etzkowitz, 1998; Christensen, 2015).

Ao promover interações com outras instituições, abrangendo funções além do ensino, a universidade estabelece relação com a teoria das hélices, inicialmente compreendendo a relação de três atores responsáveis pela geração de inovação social e posteriormente sendo aperfeiçoada pelos trabalhos de autores como Caraynnis e Campbell. Estes trabalhos englobam novos fatores, sendo a IES um dos atores chaves para o funcionamento do processo e tendo como foco do trabalho a relação com a sociedade (Leydesdorff, 2018).

\subsection{Tríplice hélice}

A Hélice Tríplice é definida como um modelo de inovação tecnológica e empreendedorismo em que a universidade/academia, a indústria e o governo interagem para promover o desenvolvimento social e o crescimento econômico, baseado no fluxo do conhecimento (Etzkowitz, 1998; Zhao et al., 2017).

O termo foi criado por Henry Etzkovitz e Leydesdorff nos anos 90 e é fundado nas três esferas institucionais supracitadas (academia, indústria e governo) denominadas hélices nessa teoria, na qual todas são independentes, mas atuam de forma cooperativa e interdependente (Bachmann, 2017).

A Hélice Tríplice se tornou um modelo muito influente na literatura da inovação, se diferenciando dos sistemas anteriores que focavam nas relações indústria-governo. Para Mineiro e Castro (2020), a indústria deixa de exercer papel central no processo de inovação, como era considerado anteriormente, e assim conta com a colaboração de novos atores (Nelson \& Rosenberg, 1993; Lundvall, 2010). Essa nova perspectiva também complementa e questiona o modelo do Triângulo de Sábato (Sábato \& Botana, 1968), onde o governo é entendido como protagonista.

Com a Hélice Tríplice, a universidade passa a agregar a função de desenvolvimento econômico, além das funções primárias de ensino e pesquisa - conforme explica a vigente Segunda Revolução Acadêmica. Do mesmo modo, as empresas precisam investir em inovação para competitividade no mercado. Dessa forma, a empresa precisa estar preparada para saber como solicitar a colaboração das universidades, relação esta que deve obter um agente intermediador (Gomes \& Pereira, 2015). 
A relação universidade-indústria-governo constitui uma cadeia de comunicação e reconhece a soberania de medidas isoladas, mas introduz a noção de trocas institucionais, realimentando os arranjos já estabelecidos. Cada hélice é responsável pelo próprio desenvolvimento e cumprimento de suas funções, entretanto interagem em termos de bens e serviços, podendo manifestar essa interação inclusive em forma de negociação, como na "universidade empreendedora" (Doin \& Rosa, 2019).

O Programa de Extensão Universitária - PROEXT é uma manifestação observável que caracteriza a relação entre as hélices. O PROEXT é uma iniciativa do governo federal e apoia a IES para incentivar projetos com ênfase na inclusão social, portanto, o governo exerce papel de moderador e disponibiliza recurso financeiro para as organizações de ensino que atenderem os requisitos vigentes em seus editais e que colaborem com o desenvolvimento de políticas públicas para promover a inovação social (MEC, 2020).

O caso de uma universidade do nordeste brasileiro mostra a relação entre governo, IES e comunidade na prática. Um projeto apoiado pelo PROEXT engaja os alunos da instituição em prol da aplicação de conhecimento adquirido no decorrer do curso para auxiliar a comunidade ao redor, uma vez que fornecem as análises microbiológicas e físico-químicas de alimentos e líquidos consumidos pelos habitantes ao entorno. Atualmente, essa mesma universidade promove seis trabalhos em parceria com o PROEXT, estabelecendo uma relação de troca com a sociedade, base do conceito de Quádrupla Hélice (Carayannis, 2017; MEC, 2020).

\subsection{Quádrupla hélice}

A ideia da tríplice hélice é inicialmente definida como uma relação entre universidade, indústrias e governo (Etzkowitz \& Leydesdorff, 2000), mas, posteriormente, outros autores ampliam a definição do conceito de acordo com o avanço da sociedade e a identificação de diferenças em suas interações. Desta forma, surge a incorporação da quarta hélice que associa uma noção de "classe criativa" às relações antes citadas, envolvendo o papel da mídia, da sociedade civil e sua cultura, e, de modo cumulativo a quíntupla hélice é uma análise interdisciplinar da estrutura do desenvolvimento sustentável e a ética ecológica agregando então o meio ambiente (Carayannis \& Campbell, 2010). A figura 2 ilustra a ampliação de relações provenientes do conceito de novas hélices. 
Figura 2.

Da Tríplice a Quíntupla Hélice

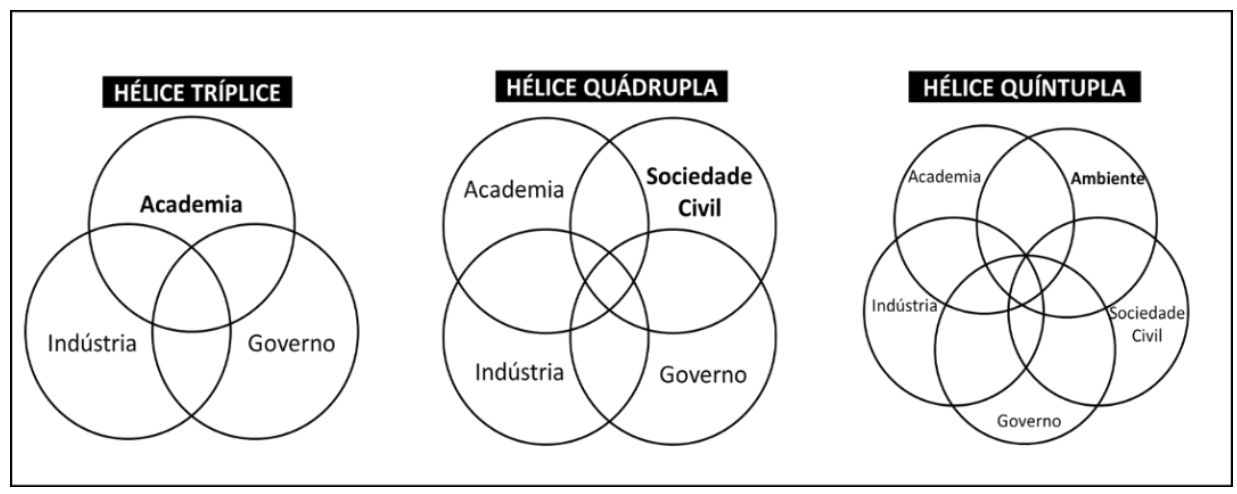

Fonte: Adaptado de Etzkowitz (1998) e Carayannis e Campbell (2010).

O foco deste trabalho se desenvolve a partir das perspectivas construídas pela quarta hélice, que gera conhecimento e inovação para a sociedade tomando a IES como ator e podendo estabelecer uma relação industrial-universitária, governamental-universitária e socialuniversitária (Carayannis, 2017).

Saad e Zawdie (2005) questionam o fator cooperação entre os atores do modelo de Hélice Tríplice uma vez que a igualdade de protagonismo entre eles não é devidamente distribuída. As hélices envolvidas também apresentam finalidades e interesses diferentes, fator que pode abalar uma correlação harmônica (Mineiro \& Castro, 2020). Importante apontar a relação necessária de coexistência entre democracia e pensamento criativo inovador para o desenvolvimento efetivo da quarta hélice, isso quando "democracia" não é compreendida por um processo eleitoral estreito e sim por um conceito mais amplo onde igualdade, liberdade, desenvolvimento sustentável e a ideia de 'qualidade de democracia' são igualmente cruciais para um processo de inovação, principalmente quando promovida pelas IES (Carayannis \& Campbell, 2015).

\subsection{Inovação social}

Inovação social é uma reconfiguração de práticas sociais através da ação de diversos atores, a fim de corresponder às demandas de uma sociedade sejam elas problemas ou a necessidade de desenvolvimento (Howaldt \& Schawarz, 2010).

O caráter prático desta inovação, como é colocado por Santos (2012), pode ser observado através das IES pelo desenvolvimento de suas dimensões de ensino até pesquisa científica e finalmente sua extensão e disseminação transcendendo os limites acadêmicos. 
De acordo com Juliani (2015), o cerne da inovação social parte do princípio de que a inovação focada para a manutenção da competitividade das organizações no mercado não se mostra mais satisfatória. Sendo assim, o âmbito social é colocado em evidência assumindo um caráter não mercantil, as pesquisas e estudos passam a trabalhar, a fim de proporcionar uma melhoria significativa na qualidade de vida das pessoas - a partir da mudança das tradições estabelecidas - e passa-se a investir na interação dos atores mais impactantes para os indivíduos de uma determinada região.

As definições mais abrangentes apresentam o alcance que a inovação social pode atingir ao mesmo tempo em que sua possível saturação e perda de impacto real, como é definido por Phills, Deiglmeier e Miller (2008) e Miller (2018). Assim, é importante entender o termo não somente enquanto produto ou serviço, mas também movimento social, ideias e outras formas de manifestações.

Corroborando com essa visão, Cajaiba-Santana (2014) relata que a estrutura da inovação social se difere principalmente por ser imaterial, não configurando um artefato técnico palpável diretamente, mas sim a institucionalização de novas práticas que promovam efeitos qualitativos e quantitativos.

Esses efeitos citados promovem um processo de troca de conhecimento, constituindo uma situação ganha-ganha: a própria universidade se beneficia das vantagens geradas pelo processo de extensão - que possui características indissociável do estudo e pesquisa - gerando oportunidades e alavancando o desenvolvimento econômico-social e o aumento de recursos intelectuais. Desta forma, perpetua-se a importância, impacto e inovações advindas das IES. (Faria, 2004; Vorley \& Nelles, 2008; FORPROEX, 2012).

\section{Metodologia}

Para Cervo (2007), há método fundamentalmente igual para todas as ciências, o qual está estruturado em observação, descrição, comparação, análise e síntese, e tem por objetivo propor problemas e levantar hipóteses, registrar os dados observados para responder à questão formulada - como ocorre o processo de inovação social dentro de uma IES? - e elaborar explicações de acordo com os dados levantados no estudo de caso. A natureza da pesquisa é qualitativa e quantitativa de caráter exploratório, por intermédio da análise de estudo de caso.

Para o levantamento de dados, foram utilizadas quatro formas de coleta, sendo que para a pesquisa qualitativa foram realizadas entrevistas roteirizadas com os responsáveis pelos projetos sociais da instituição (Diretora da IES e Professor responsável pelo projeto) e grupo 
focal, contando com a participação dos alunos do curso de engenharia da computação participantes do comitê do projeto em análise. A pesquisa documental, em apuração dos dados disponibilizados pela instituição para compreender os impactos socioeconômicos de suas ações sociais (como empregabilidade, renda dos beneficiários das ações sociais). E para a pesquisa quantitativa foi disponibilizado questionário estruturado em ferramenta online, com a participação total de 15 alunos envolvidos no projeto em andamento. Esse questionário teve por finalidade identificar a percepção desses alunos em relação aos benefícios e às competências desenvolvidas decorrentes da participação no projeto.

O trabalho foi desenvolvido utilizando revisão bibliográfica de materiais atualizados extraídos dos sites da Scielo e Spell, revistas com classificação igual ou superior à B2, além de teses, dissertações, artigos e livros, conforme ilustra o quadro 1.

\section{Quadro 1.}

\section{Estrutura Bibliográfica}

\begin{tabular}{|l|l|}
\hline Fonte de dados & $\begin{array}{l}\text { Biblioteca Eletrônica Científica Online SciELO; } \\
\text { Biblioteca Eletrônica de Periódicos Científicos SPELL; } \\
\text { Google Acadêmico }\end{array}$ \\
\hline Tipo de lite ratura & Artigo científico, dissertações, livros, revistas, sites e teses \\
\hline Idiomas & Inglês e Português \\
\hline Class ificação & A2, B1, B2 \\
\hline
\end{tabular}

Fonte: Desenvolvido pelos autores (2021).

A revisão ocorreu acerca dos temas de Inovação Social, Segunda Revolução Acadêmica, Tríplice e Quádrupla Hélice, tomando por base os estudos conjuntos de Etzkowitz e Leydesdorff aprofundados por Carayannis e Campbell.

A relação com os estudos dos temas citados com as ações realizadas pela IES estudada motivou a escolha do estudo de caso, pois a IES parceira corrobora com a ideia da Segunda Revolução Acadêmica ao proporcionar programas e projetos voltados para comunidade. Tais programas envolvem o desenvolvimento de propostas que atendam às necessidades habitacionais da região em que está inserida, promovendo maior aderência acadêmica a temas corporativos, transformação social e construindo um fluxo cíclico de colaboração, uma vez que esses alunos empregam conhecimentos adquiridos ao longo do processo acadêmico de forma a transformar o âmbito social.

Por fim, o trabalho utilizou as ferramentas de gestão para trabalhar os dados coletados e ter insumos científicos para a elaboração de um roadmap, que possibilitará às outras IES como 
conduzir ações geradoras de inovação social, no modelo de empreendedorismo e inovação da Quádrupla Hélice.

\section{Resultados e discussão}

Para relacionar o referencial teórico pesquisado aos dados coletados por meio de entrevistas semiestruturadas, grupo focal e questionário estruturado, esta seção apresenta a análise dos resultados encontrados em cinco partes sendo, respectivamente: a caracterização da IES, entrevistados, respondentes do questionário aplicado; a IES sob a perspectiva da inovação social; o posicionamento da IES frente à Segunda Revolução Acadêmica e Quádrupla Hélice; os desafios e resultados do projeto analisado; e, por fim, a proposta do roadmap para implantação de projetos de inovação social em IES, a fim de promover a IES como indutora da transformação social.

\subsection{Caracterização da IES, dos entrevistados e respondentes}

A IES localizada na região do grande $\mathrm{ABC}$ é uma organização privada sem fins lucrativos, e tem como visão ser uma entidade modelo de promoção de transformação social em território nacional. Estima-se 1800 alunos entre cursos de bacharelado e pós-graduação, atualmente reconhecidos pelo MEC nos cursos de Engenharias e Administração.

As entrevistas foram realizadas com cinco membros da IES envolvidos com o projeto analisado de inovação social, dividido em duas entrevistas e pesquisa realizada com um grupo focal. Os entrevistados são: o coordenador dos projetos de extensão universitária e a diretora acadêmica, e o grupo focal é composto por três integrantes do comitê do projeto, alunos do curso de Engenharia da Computação. O questionário estruturado foi aplicado para os alunos voluntários do projeto estudado e obteve quinze respondentes. $\mathrm{O}$ quadro 2 detalha as características das coletas:

\section{Quadro 2.}

\section{Caracterização das Coletas}

\begin{tabular}{|l|l|r|l|l|}
\hline Tipo de coleta & Papel no projeto analisado & Data de aplicação & Tempo de entrevista & Meio utilizado \\
\hline Entrevista 1 & Professor Coordenador do projeto & $11 / 09 / 2020$ & $1 \mathrm{~h} 55$ minutos & Aplicativo Teams \\
\hline Entrevista 2 & Diretora acadêmica & $26 / 09 / 2020$ & $1 \mathrm{~h} \mathrm{37}$ minutos & Aplicativo Teams \\
\hline Grupo focal 1 & 03 Alunos de engenharia da computacão do comitê & $03 / 10 / 2020$ & 56 minutos & Aplicativo Teams \\
\hline Questionário 1 & 15 Alunos participantes do projeto & $03-17 / 10 / 2020$ & - & Google Forms \\
\hline
\end{tabular}

Fonte: Desenvolvido pelos autores (2021). 


\subsection{A IES e a inovação social}

O projeto de inovação social estudado teve início no ano de 2017, com propósito de promover uma formação multidisciplinar aos alunos através do voluntariado. A ideia do projeto foi proposta pelo mesmo professor o qual permanece na liderança e responsabilidade. Atualmente, o projeto é enquadrado como extensão universitária, cumprindo as definiç̧ões e diretrizes do Plano Nacional de Extensão. Esse projeto obteve o reconhecimento no Prêmio Nacional de Gestão Educacional - PNGE, na categoria de responsabilidade social.

O conceito de inovação social de Phills, Deiglmeier \& Miller (2008) é abrangente, caracterizando a sua possibilidade de ser como produto, processo de produção/tecnologia, princípios, ideias, legislações etc. Em entrevista, a diretora acadêmica da IES estudada (informação verbal) ${ }^{1}$ diz que: “A inovação social é uma forma de perpetuação de modelos de atuação na sociedade mais coerentes", explicando que, em sua opinião, a inovação social deve ser aplicada na prática e demonstrar resultados eficazes para que assim seja caracterizada. A diretora discorre sobre a necessidade de que a inovação social seja efetiva em espectro coletivo e não individual, demonstrando-a como abordagem necessária para resolução de problemas sociais, essas afirmações reforçam o protagonismo que a IES exerce nesse processo e que a inovação social é uma reconfiguração de práticas sociais através da ação de diversos atores, a fim de corresponder às demandas de uma sociedade (Howaldt \& Schawarz, 2010).

A diretora acadêmica destaca que as IES possuem um alto potencial no processo de inovação social, já que possuem uma massa crítica da sociedade (alunos), além de reconhecer como papel da IES o desenvolvimento social e econômico. Atrelando esses dois fatores, temse a IES como instituição propícia e ideal para resolução de problemas sociais por meio da inovação social.

Já o coordenador do projeto explica que o conceito de inovação social, em sua visão, está atrelado ao conceito de economia circular. Basicamente, acredita que se desenvolve uma solução para um problema social, que quando aplicada se mostra eficaz; e, então, aplica-se o mesmo modelo para demais casos, regiões e países, expandindo seus efeitos que melhoram e/ou solucionam problemas sociais. Dessa forma, destaca-se o benefício da inovação social como soluções de problemas sociais que possuem alto potencial de replicação e expansão, demonstrando impactos positivos para a sociedade em larga escala.

\footnotetext{
${ }^{1}$ Informação verbal concedida pela diretora acadêmica da IES analisada, em entrevista, no dia 26 de setembro de 2020.
} 
Para os alunos do comitê do projeto estudado, um dos motivos que facilita o processo de inovação social é a faculdade ter em sua cultura o papel de transformação social. Em entrevista, um dos alunos destaca (informação verbal) $)^{2}$ que a IES estudada "tem uma visão de ajudar a sociedade, é mais fácil conseguir voluntários”, requisito primário e fundamental para dar início aos projetos sociais dentro de uma IES. O grupo focal relata como a cultura altruísta e de transformação social da IES constrói estes valores no corpo discente, que passam a tê-los como valores pessoais também. Sendo assim, a pesquisa confirma o potencial da IES de promover cidadãos voluntários através de sua cultura e projetos de inovação social.

\subsection{A IES na segunda revolução acadêmica e quádrupla hélice}

Os entrevistados em sua totalidade transparecem a concordância com a teoria da Segunda Revolução Acadêmica no que tange ao papel da IES, que agrega a função de desenvolvimento econômico e social além do ensino e a pesquisa à academia (Etzkowitz, 1999). A diretora (informação verbal) ${ }^{3}$ cita que "a indústria vai se movimentar (para atender as altas demandas da sociedade) e usa a conexão com a faculdade para trazer conhecimento e tecnologia", assim como destaca Costa (2018) ao utilizar o termo "ensino empresarial" e suas contribuições de conhecimento e tecnologia à sociedade.

O responsável pelo projeto diz que há uma necessidade de (informação verbal) ${ }^{4}$ : “[...] fazer parcerias para que essas ONGs possam sobreviver", fomentando a necessidade de investimentos financeiros e intelectuais de outras instituições em ONGs, conforme modelo de interação entre instituições sociais, abordadas no modelo de Hélice Quádrupla (Carayannis \& Campbell, 2010) que atrela o governo, academia, empresa e sociedade civil para promoção de inovação e empreendedorismo.

Da mesma forma que as críticas sobre a Quádrupla Hélice pontuadas por Saad e Zawdie (2005) referentes à vulnerabilidade do modelo pela distribuição desigual de poder entre as esferas e por Mineiro e Castro (2020) que apontam a divergência dos atores das hélices, a direção acadêmica pontua (informação verbal) ${ }^{5}$ que a falha na relação das esferas organizacionais abordadas na teoria é "[...] não ter objetivos comuns". Ela relata que as três esferas da Hélice Tríplice - governo, academia e empresa - são compostas pela própria sociedade e, por isso, enxerga a Hélice Quádrupla como uma formalização de uma relação que

${ }^{2}$ Informação verbal concedida pelos alunos integrantes do comitê do projeto analisado, em entrevista, no dia 03 de outubro de 2020.

${ }^{3}$ Informação verbal concedida pelos alunos integrantes do comitê do projeto analisado, em entrevista, no dia 03 de outubro de 2020 ${ }^{4}$ Informação verbal concedida pelo coordenador do projeto analisado, em entrevista, no dia 11 de setembro de 2020.

${ }^{5}$ Informação verbal concedida pelos alunos integrantes do comitê do projeto analisado, em entrevista, no dia 03 de outubro de 2020. 
já existia; em suas palavras (informação verbal) ${ }^{6}$ “a quádrupla hélice já existia de forma não formal".

\subsection{O projeto de inovação social: resultados e desafios}

O programa de inovação social estudado foi implantado em 2017, com o envolvimento dos seguintes atores e papéis no projeto, respectivamente: o responsável pelo projeto, para a formulação da proposta, cronograma, escolha e visitas à ONG parceira, apresentação aos alunos, captação de alunos, formação do comitê e orientação do projeto como um todo; a direção acadêmica, para avaliação e aprovação do projeto, alinhando-o com os objetivos estratégicos e cultura da IES; a coordenação acadêmica, para contribuir a avaliar a escolha da ONG; professores, como suporte intelectual às demandas dos alunos ao decorrer do projeto; do comitê, composto pelos próprios voluntários, mantendo o elo entre alunos e responsável pelo projeto; e, por fim, alunos, como voluntários e desenvolvedores do projeto. A figura 3 mostra o fluxograma que a IES utilizou para implantar o programa de inovação social.

\section{Figura 3.}

Fluxograma Utilizado Pela IES ao Implantar o Programa de Inovação Social

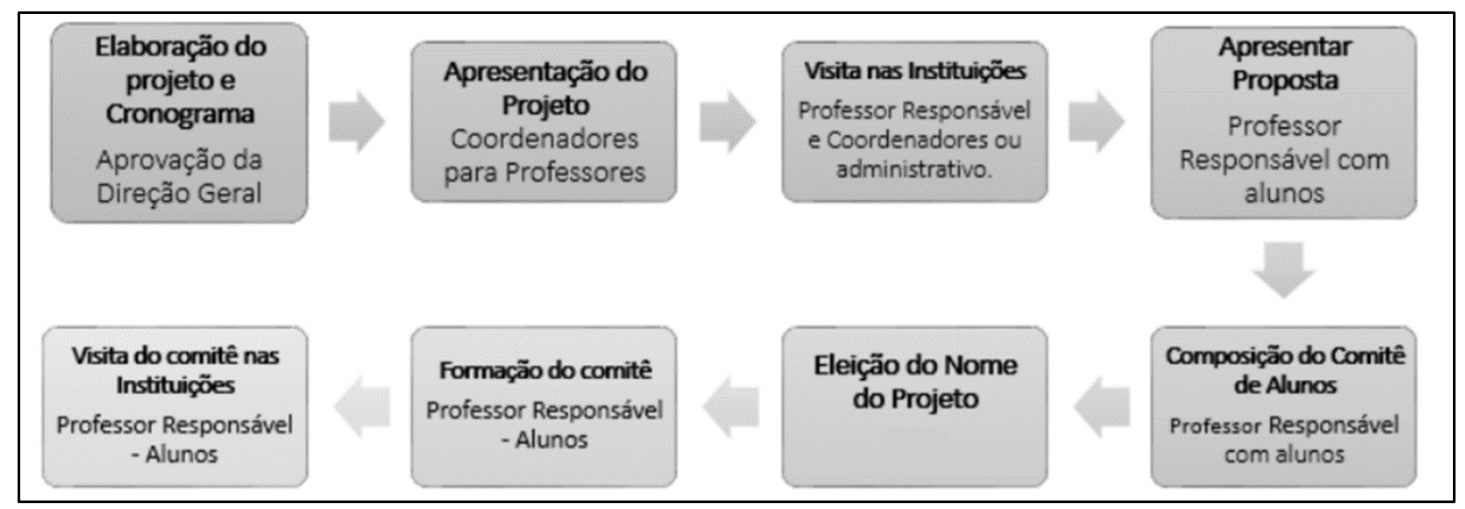

Fonte: Dados fornecidos pela IES estudada (2018).

O projeto analisado é o segundo realizado pelo programa de inovação social, teve início em 2019 e permanece em andamento, conforme período de duração de 24 meses estipulado pelo responsável pelo projeto. Tem como instituição parceira uma ONG da mesma cidade da IES que atende o público dos 6 aos 60 anos, desenvolvendo ações sociais para prevenir

\footnotetext{
6 Informação verbal concedida pelos alunos integrantes do comitê do projeto analisado, em entrevista, no dia 03 de outubro de 2020.
} 
situações de risco e fortalecer a convivência familiar e comunitária, oferecendo ações complementares à escola, apoio psicossocial e sociofamiliar.

Dentre os resultados e impactos provenientes da inovação social para os voluntários, o projeto estudado apresenta em seu relatório de extensão universitária seus objetivos de aprendizagem, que incluem tanto o desenvolvimento de ações na IES em prol da comunidade externa, quanto o desenvolvimento de 12 competências nos alunos participantes do projeto. Em pesquisa, $100 \%$ dos voluntários identificaram o desenvolvimento de parte dessas delas, sendo a competência desenvolvida com maior representatividade na visão dos alunos, diagnosticada em questionário, a "solidariedade e altruísmo" (93,3\%) seguida pela "responsabilidade social" (86,7\%); e, as menos desenvolvidas: "conhecimentos acadêmicos e técnicos", "liderança" e "inteligência emocional" (40\% cada), conforme figura 4 demonstra os resultados do questionário feito com os voluntários do projeto estudado:

\section{Figura 4.}

Questionário: Competências Desenvolvidas nos Alunos Decorrentes do Projeto

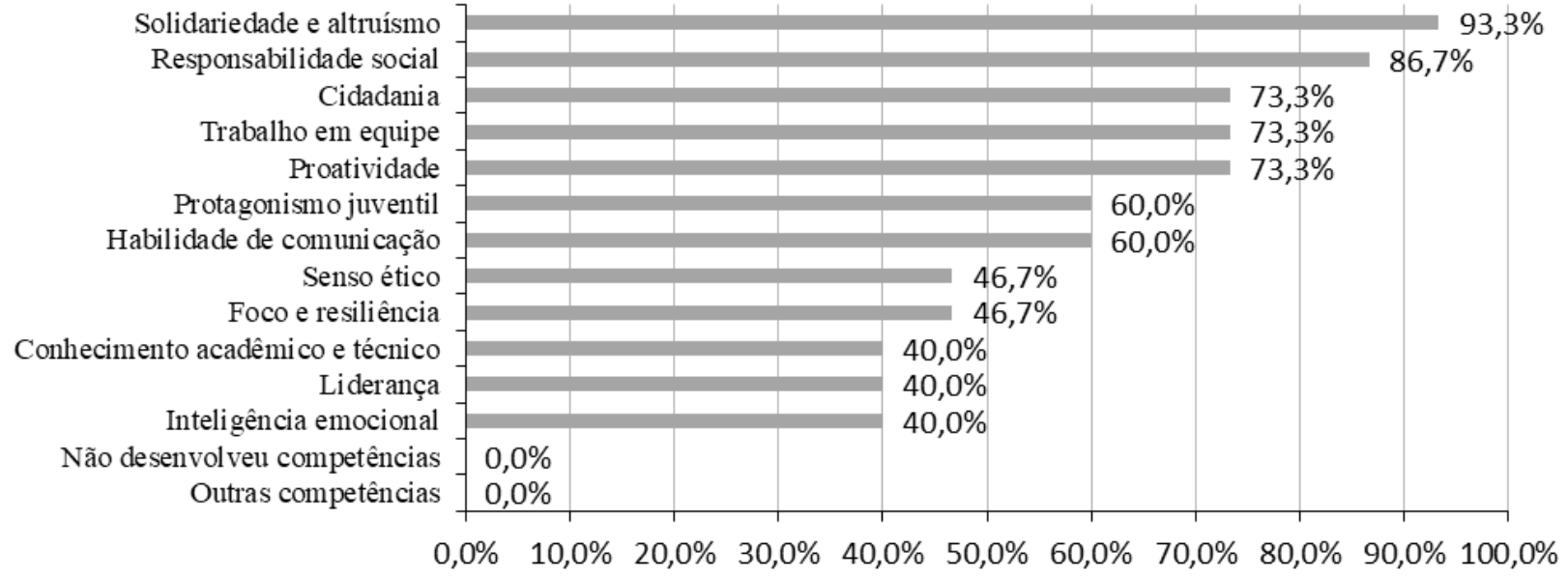

Fonte: Desenvolvido pelos autores (2021).

Além disso, os alunos do comitê destacaram o desenvolvimento de conhecimentos técnicos e o diferencial competitivo que a participação no projeto agregou a eles no mercado de trabalho. Eles sugerem às faculdades que possuem dificuldade de inserir o aluno no mercado de trabalho a implantação de um programa social que devolve o conhecimento técnico que alavanca a carreira do aluno, como meio de aumentar a empregabilidade e atrair a participação e retenção dos alunos. O grupo focal menciona (informação verbal) ${ }^{7}$ "Só de citar que a gente 
trabalhava em um projeto social [...] os gestores ficavam com os olhos brilhando! Era algo extremamente bem-visto no momento da entrevista", explicando o benefício de destaque profissional.

Como resultados para a ONG auxiliada pelo projeto, em questionário aplicado aos alunos voluntários do projeto, comenta-se que "As instituições ajudadas são capazes de ganhar sua própria fonte de renda após a implementação de projetos voltados a venda de bens ou serviço prestados pela instituição", "Aumentar o acesso à cultura/educação e fornecer melhor qualidade de vida" e "Suporte nos mais diversos âmbitos da Instituição, como gestão financeira, recursos humanos, marketing, e oportunidades para parcerias". Desta forma, verifica-se os impactos e benefícios decorrentes da inovação social, afirmando o potencial de transformação social promovido pela IES.

Constata-se que o projeto incentiva a prática do voluntariado nos alunos de forma autônoma. Em questionário, foi diagnosticada uma participação de $60 \%$ dos respondentes em trabalho voluntário antes da participação no programa; após o projeto, $60 \%$ pretendem atuar em outros projetos voluntários, 33,3\% talvez atuem, e 6,7\% não pretendem.

O principal desafio encontrado para o desenvolvimento do projeto de inovação social analisado é a retenção e o engajamento dos alunos voluntários. Os alunos do comitê relatam que as desistências foram o motivo de sobrecarga de atividades para os alunos que permaneceram até o fim do projeto, dificultando a entrega final à ONG. Além disso, o grupo focal relata a não utilização de ferramentas de gestão e de projetos para planejamento e execução das atividades, reconhecendo este gap como prejudicial ao projeto.

Alunos do comitê (informação verbal) $)^{8}$ contam que: “ [...] O grupo de engenharia da computação começou com mais de 20 alunos participando, e quando foi decidido o que iria ser feito, existiam essas 20 pessoas [..] durante a etapa de organização do projeto, essas pessoas foram saindo e quando chegou o momento de executar o projeto, resumiu em três alunos".

O coordenador do projeto afirma a desistência dos alunos como principal desafio para o projeto de inovação social, comentando (informação verbal)": "Persistência e engajamento: desenvolver isso neles que é uma habilidade", destacando que, apesar da importância do desenvolvimento dessas competências para o projeto em si e como cidadãos, há uma dificuldade em desenvolvê-las nos alunos. Foi possível detectar a participação dos respondentes no projeto, comprovando a desistência em $73 \%$ dos alunos em 18 meses ou menos, considerando que os

\footnotetext{
${ }^{8}$ Informação verbal concedida pelos alunos integrantes do comitê do projeto analisado, em entrevista, no dia 03 de outubro de 2020

${ }^{9}$ Informação verbal concedida pelos alunos integrantes do comitê do projeto analisado, em entrevista, no dia 03 de outubro de 2020
} 
projetos possuem duração de dois anos. O quadro 3 demonstra os resultados do questionário aplicado, sobre o período de participação no projeto:

\section{Quadro 3.}

Respondentes do Questionário

\begin{tabular}{|l|l|l|l|l|l|}
\hline Período de participação no projeto & $0-6$ meses & $7-12$ meses & $13-18$ meses & $19-24$ meses & 25 meses ou mais \\
\hline Representatividade & $33 \%$ & $20 \%$ & $20 \%$ & $20 \%$ & $7 \%$ \\
\hline
\end{tabular}

Fonte: Desenvolvido pelos autores (2021).

Outro ponto de melhoria diagnosticado no projeto é a sua divulgação interna e externa. Um dos alunos do comitê (informação verbal) ${ }^{10}$ destaca que "[...] por mais que tenha uma divulgação quando o resultado tá pronto, falta uma divulgação quando tá em processo", fator que acredita que ajudaria na retenção e captação de voluntários.

Como oportunidade, diagnosticou-se a inclusão de alunos egressos ao projeto como meio de retenção e engajamento dos alunos, além da possibilidade de networking e compartilhamento de conhecimentos teóricos e práticos. Em questionário aplicado, constatouse que $60 \%$ participaria do projeto como egresso e os outros $40 \%$ talvez participariam, não obtendo nenhum voto de rejeição.

\subsection{Proposta de diretrizes para a transformação social}

Com o modelo do programa de inovação social analisado pelo estudo de caso, foi diagnosticado o fluxograma do projeto em seus pontos positivos e os de melhoria, e, a partir deles, propõe-se um plano de ação disposto em roadmap para implantação de projetos de inovação social em IES, com o intuito de promovê-la como indutora da transformação social.

A partir da análise dos resultados, sugere o modelo de roadmap para implantação, desenvolvimento e finalização de projetos de inovação social em IES no período de dois anos. O período de desenvolvimento do projeto sofreu uma redução com o intuito de torná-lo mais rápido e atrativo aos alunos, auxiliando na retenção e engajamento dos mesmos. Apresenta em seu eixo horizontal a duração de cada etapa e atividade; verticalmente, o roadmap apresenta os atores envolvidos, sendo: direção acadêmica, coordenação dos cursos e professores, responsável pelo projeto, alunos voluntários e ONG a ser beneficiada; e, por fim, as atividades

${ }^{10}$ Informação verbal concedida pelo coordenador do projeto analisado, em entrevista, no dia 11 de setembro de 2020. 
diferenciadas por cores representando as três grandes etapas de desenvolvimento, sendo elas, respectivamente: pré-projeto, projeto e pós projeto. A figura 5 mostra o roadmap para implantação de projetos de inovação social em IES:

\section{Figura 5.}

Roadmap Para Implantação de Projetos de Inovação Social em IES

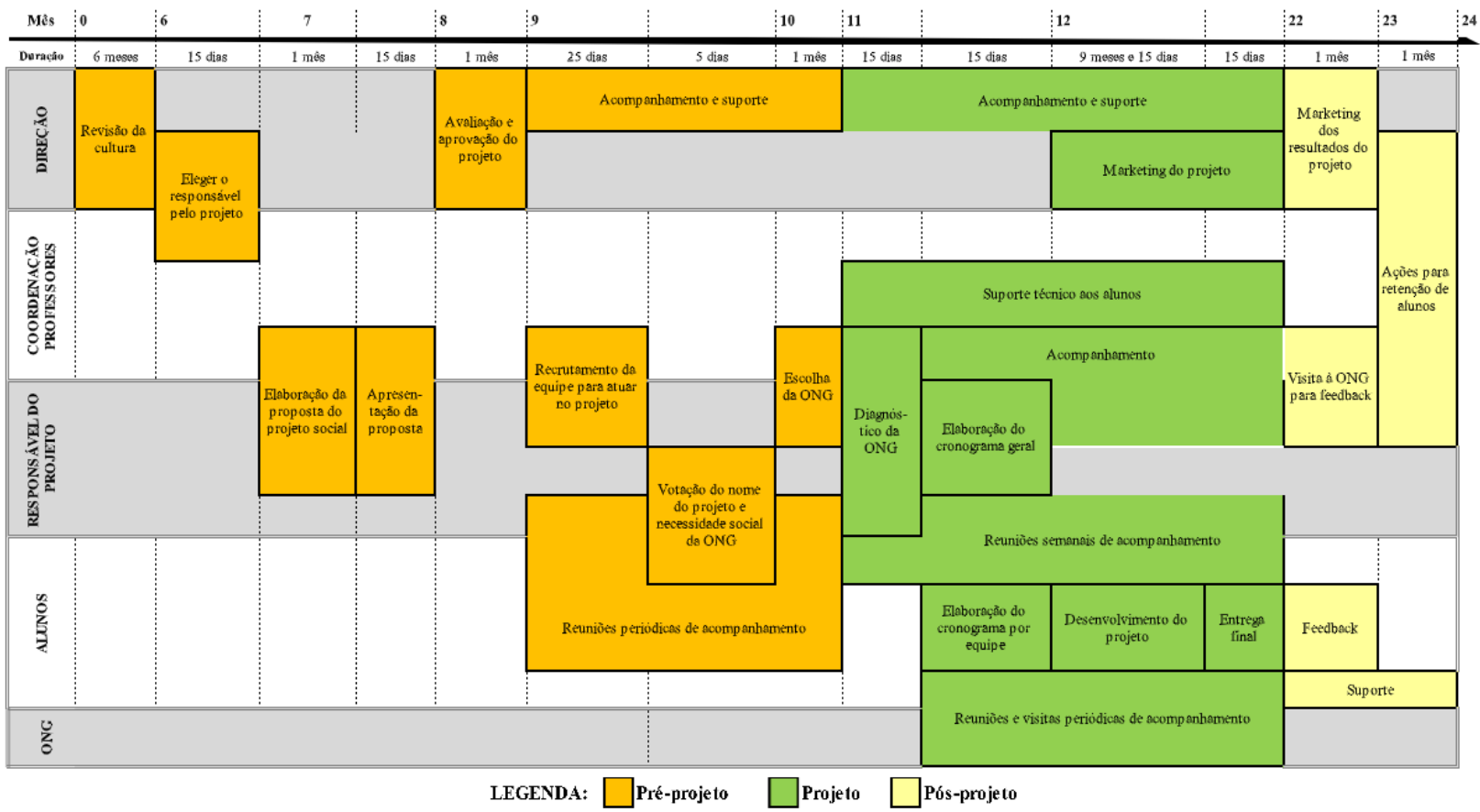

Fonte: Desenvolvido pelos autores (2021).

A etapa de pré-projeto tem duração de 11 meses e tem como objetivo geral implantar na IES a cultura de responsabilidade pela transformação social, e, a partir daí, iniciar os esboços do projeto de inovação social. Os resultados apontam que a compreensão da IES de seu papel institucional, conforme teorias de Quádrupla Hélice e Segunda Revolução Acadêmica, é imprescindível para iniciar os projetos. Desta forma, a IES passa este valor tanto para os docentes, colaboradores e alunos. Esta etapa é majoritariamente estratégica, tendo como principais atores a direção acadêmica, coordenação de cursos, professores e o responsável pelo projeto.

Ainda no pré-projeto, o responsável pelo projeto, professores e coordenadores trabalham no planejamento e na apresentação da proposta aos alunos, que se inscrevem para participar do projeto. Com a equipe de voluntários formada, realiza-se a votação do nome do projeto e da fragilidade social/público-alvo que desejam atuar. A partir disso, os coordenadores de cursos e o responsável pelo projeto realizam a triagem de ONGs da região, de acordo com o 
tema votado pelos alunos. As ONGs finalistas passarão por visitas e análises dos dois últimos atores mencionados, avaliando questões legais de funcionamento, prestação de contas ao governo, fidedignidade de informações e relatórios contábeis, a coerência com o propósito dos alunos e o espaço para desenvolvimento e aplicação de inovação social. Aquela que se apresentar dentro dos quesitos pré-estabelecidos e mais se alinhar ao objetivo dos alunos, será escolhida como ONG parceira do projeto.

Durante o projeto, estima-se um período de 11 meses focado no desenvolvimento da inovação social. Ocorrerá a divisão das equipes por cursos, que autodenominarão dois líderes por equipe para composição do comitê. Juntamente aos alunos, o responsável pelo projeto realiza visitas presenciais à ONG parceira para diagnóstico dos problemas e oportunidades. O responsável pelo projeto apresentará aos alunos o cronograma geral dos prazos e expectativas de grandes etapas, o desenvolvimento do projeto e a entrega final. Os alunos definirão o que será entregue e como será desenvolvido, utilizando ferramentas de gestão e de projetos, como sugestão Microsoft Project ou Trello, para melhor organização, fluidez e divisão de atividades, com o intuito de diminuir a sobrecarga de atividades e tempo devido a desistência de alunos.

Os professores e coordenação prestam suporte aos alunos, oferecendo os conhecimentos técnicos que forem necessários durante o projeto. Estes dois atores - professores e coordenadores de curso - atuam em parceria com o foco de caracterizar o projeto de inovação social como multidisciplinar, relacionando as matérias teóricas na prática e criando uma relação entre os cursos por meio de matérias semelhantes. Esses atores são peças-chave para o projeto, pois estão em contato próximo com os alunos da IES, auxiliando na retenção e engajamento dos alunos durante o projeto.

A etapa do projeto conta com reuniões semanais entre os voluntários e responsável pelo projeto na IES para acompanhamento, mentoria e supervisão do projeto, demonstrando também os resultados e etapas de desenvolvimento. O responsável pelo projeto reporta o desenvolvimento do projeto aos professores e coordenação, que trabalharão a divulgação interna e externa, com o intuito de acompanhar, reconhecer, manter e incentivar o engajamento dos voluntários no projeto. Esses reportes também passarão para a direção, que é responsável por alinhar o projeto com a cultura organizacional da IES. Além disso, estima-se visitas periódicas à ONG para implementação e acompanhamento do projeto pelos alunos. As atividades deste parágrafo possuem, sobretudo, o intuito de reduzir a evasão dos alunos ao decorrer do projeto, pois demonstram acompanhamento assíduo com suporte e orientação do responsável pelo projeto, permitem a visualização macro de todas as equipes, atribuem 
responsabilidades, permitem que a evolução do projeto seja visualizada presencialmente na ONG e que esta seja compartilhada internamente e externamente pela IES, promovendo visibilidade e reconhecimento aos voluntários.

Por fim, com a conclusão do projeto, a fase do pós-projeto tem duração de dois meses e baseia-se nos feedbacks da ONG, na divulgação dos resultados e nas ações para promover a retenção dos alunos que participaram, sejam eles como egressos ou alunos. Esta etapa também é composta pelo suporte e acompanhamento dos alunos à ONG. O pós-projeto tem como relevância e foco a retenção de alunos que já participaram do projeto, incluindo os egressos para suprir os gaps de "falta de tempo", apontados como maior fator para desistência dos alunos no projeto analisado em estudo de caso, além da função de mentoria e networking que esta inclusão oferece. Os participantes recebem o certificado de participação no projeto, que pode ser contabilizado como horas complementares para a conclusão do curso.

\section{Considerações finais}

Essa pesquisa teve como objetivo geral analisar como o processo de inovação social acontece dentro de uma Instituição de Ensino Superior e propor um roadmap facilitador para promover a transformação social, por intermédio da implementação de atividades de extensão universitária. Além das etapas, prazos e responsabilidade dos envolvidos, foi possível compreender a influência social que uma IES pode exercer em torno de sua região, adquirindo um importante papel no processo de transformação social das pessoas que vivem nessas comunidades

Os resultados também apontam que, além da melhoria de vida em sociedade através da democratização de conhecimento e tecnologia, os próprios alunos ganham uma bagagem humanitária que pode ser extremamente importante para a construção de uma sociedade mais empática. Foi diagnosticada a oportunidade de formar grupos de estudo extracurricular que venha a aumentar a empregabilidade do indivíduo. Portanto, o envolvimento social existente nesses processos proporciona vantagens individuais e coletivas que são propulsoras da colaboração em comunidade e formadora de uma cadeia de trocas, abastecendo o mercado, a sociedade e a IES.

Esse papel vem ao encontro do que se espera de uma IES no contexto da Segunda Revolução Acadêmica, democratizando a pesquisa para que o conhecimento científico tome proporções sociais. Dessa forma, as IES podem promover a prática empreendedora para que todos os atores envolvidos no processo estabeleçam o fortalecimento da relação de benefício 
mútuo e consequentemente alcancem o desenvolvimento econômico e social das comunidades beneficiadas pelos projetos de parceria.

Nesse processo, o aluno cresce quando adquire maior especialização e experiência, gerando melhores oportunidades de emprego que, por sua vez, irão abastecer o ator-indústria, potencializado pelo conhecimento adquirido desse indivíduo. $\mathrm{O}$ ator-comunidade será beneficiado ao ter uma necessidade suprida por intermédio dessa relação. Por fim, o atoruniversidade cumpre com sua responsabilidade social e obedece à relação da Quádrupla Hélice, colaborando para uma sociedade mais igualitária.

Em relação à contribuição prática, os resultados do trabalho possibilitaram a proposição de um roadmap para auxiliar a IES na geração de transformação social, por intermédio do desenvolvimento de projetos de extensão universitária, bem como na promoção de inovação social. O roadmap desenvolvido promove o entendimento da complexidade de gerenciamento dos processos e atores envolvidos e, portanto, é dividido em três grandes momentos: préprojeto, agindo no desenvolvimento de condições para a inovação social tomar espaço; projeto, atuando na execução da inovação social; e pós-projeto, visando a perpetuação e multiplicação de projetos sociais.

Esse trabalho também contribui para políticas públicas, tendo em vista que seus resultados buscam promover a facilitação da IES para o cumprimento de, no mínimo, $10 \%$ (dez por cento) do total da carga horária curricular estudantil dos cursos de graduação para as atividades de extensão, conforme estabelecido na Resolução ${ }^{\circ}$ 7, de 18 de dezembro de 2018.

Para atingir o objetivo proposto, o trabalho buscou os principais representantes das hélices envolvidas, entretanto não foi possível um contato aprofundado com a comunidade beneficiada. Sendo assim, destaca-se como limitação do trabalho a ausência de uma entrevista com o porta-voz da comunidade. Outra limitação foi a falta de visitas para estudo de campo devido à necessidade de distanciamento social causada pela eclosão da pandemia de 2020. As visitas poderiam representar grande valor ao aproximar o normal absoluto da instituição beneficiada à análise da pesquisa, as nuances e possíveis interferências encontrariam menos espaço de atuação.

Após essas considerações, recomenda-se um olhar aprofundado para as demais hélices estabelecidas na teoria da Quádrupla Hélice, analisando o comportamento e possíveis rotas seguidas pelo governo e indústria durante o processo de incentivo à transformação social. Além disso, pesquisas futuras também poderiam se beneficiar desses resultados para estudos comparativos entre IES públicas e privadas, analisar a longevidade do modelo proposto e grau de assertividade, visto a existência de peculiaridades e propósitos de diferentes IES e por fim, 
promover estudos quantitativos com gestores de IES, alunos e comunidades beneficiados pelo projeto de inovação social para verificação de hipóteses sobre a gestão e benefícios alcançados pelos projetos de extensão.

\section{Referências}

Almeida, D. R., \& Cruz, A. D. A. (2015). O Brasil e a segunda revolução acadêmica. Interfaces da Educação, 1(1), 53-65.

Bachmann, A. M. R. (2017). Extensão universitária e inovação social: estudo na Universidade Regional de Blumenau. Dissertação (Mestrado em Administração) - Programa de Pós-Graduação em Administração, Universidade Regional de Blumenau, BlumenauSC.

Brasil. (2020). Ministério da Educação. Disponível em: http://portal.mec.gov.br/. Acesso em 30 de ago. de 2020.

Cajaiba-Santana, G. (2014). Social innovation: Moving the field forward. A conceptual framework. Technological Forecasting and Social Change, 82, 42-51.

Carayannis, E. G., \& Campbell, D. F. (2010). Triple Helix, Quadruple Helix and Quintuple Helix and how do knowledge, innovation and the environment relate to each other?: a proposed framework for a trans-disciplinary analysis of sustainable development and social ecology. International Journal of Social Ecology and Sustainable Development (IJSESD), 1(1), 41-69.

Carayannis, E.G., \& Campbell, D.F.J. (2015). Art and artistic research in quadruple helix innovation systems. In G. Bast, E. G. Carayannis, D. F. J. Campbell (Eds.). Arts, Research, Innovation and Society. New York, NY.

Carayannis, E. G., Grigoroudis, E., Campbell, D. F., Meissner, D., \& Stamati, D. (2018). The ecosystem as helix: an exploratory theory-building study of regional co-opetitive entrepreneurial ecosystems as Quadruple/Quintuple Helix Innovation Models. $R \& D$ Management, 48(1), 148-162.

Cervo, A. L., \& Bervian, P. A. (1980). Metodologia científica. McGraw Hill.

Christensen, C. M., Raynor, M. \& McDonald, R. (2015). 'What is disruptive innovation?'. Harvard Business Review, 93, 44-53.

Costa, R. C. (2018). A pegada ideológica na narrativa da segunda revolução académica. Análise crítica da construção de um paradigma. Revista Crítica de Ciências Sociais, (116), 49-70.

da Costa, L. F., Dorion, E. C. H., \& Olea, P. M. (2016). Produção Acadêmica Sobre Inovação Social em Programas de Mestrado e Doutorado Brasileiros. In XVI Mostra de Iniciação Científica, Pós-graduação, Pesquisa e Extensão. 
Doin, T., \& Rosa, A. R. (2019). Interação universidade-empresa-governo: o caso do programa de cooperação educacional para transferência de conhecimento Brasil-Cingapura. Cadernos EBAPE. BR, 17(4), 940-958.

Etzkowitz, H., \& Leydesdorff, L. (2000). The dynamics of innovation: from National Systems and "Mode 2" to a Triple Helix of university-industry-government relations. Research Policy, 29(2), 109-123.

Faria, S. Extensão universitária e suas mediações político-pedagógicas. In: Anais do $2^{\circ}$ Congresso Brasileiro de Extensão Universitária Belo Horizonte. Congresso Brasileiro de Extensão Universitária, 12 a 15 de setembro de 2004.

Forproex. Política Nacional de Extensão Universitária - Renex. Manaus, 2012. Disponível em: http://www.renex.org.br/documentos/2012-07-13-Politica-NacionaldeExtensao.pdf.

Gomes, M. \& Pereira, F., 2015. HÉLICE TRÍPLICE: UM ENSAIO TEÓRICO SOBRE A RELAÇÃO UNIVERSIDADE-EMPRESA-GOVERNO EM BUSCA DA INOVAÇÃO. International Journal of Knowledge Engineering and Management, p.137.

Howaldt, J. \& Schwarz, M., 2010. Social Innovation: Concepts, Research Fields and International Trends. 1st ed.

Instituto Brasileiro de Geografia e Estatística. Estatísticas. Sociais - IBGE. (2020). Taxa de Desemprego.

Juliani, D. P. (2015). Desenvolvimento de um framework conceitual para potencializar a inovação social nas universidades sob o enfoque da cultura organizacional. Tese (Doutorado em Engenharia e Gestão do Conhecimento) - Programa de Pós-Graduação em Engenharia e Gestão do Conhecimento, Universidade Federal de Santa Catarina, Florianópolis-SC.

Leydesdorff, L., \& Etzkowitz, H. (1998). Triple Helix of innovation: introduction. Science and Public Policy, 25(6), 358-364.

Leydesdorff, L. (2018). Synergy in knowledge-based innovation systems at national and regional levels: The Triple-Helix model and the Fourth industrial revolution. Journal of Open Innovation: Technology, Market, and Complexity, 4(2), 16.

Lundvall, B. A. (2010). National systems of innovation: Toward a theory of innovation and interactive learning (Vol. 2). Anthem press.

Miller, K., McAdam, R., \& McAdam, M. (2018). A systematic literature review of university technology transfer from a quadruple helix perspective: toward a research agenda. $R \& D$ Management, 48(1), 7-24.

Mineiro, A. A. C., \& de Castro, C. C. (2020). A Hélice Quádrupla e sua relação com a visão de futuro dos Parques Científicos e Tecnológicos consolidados no Brasil. Revista de 
Administração, Sociedade e Inovação, 6(2), 71-89. Disponível em:

https://rasi.vr.uff.br/public/site/images/PDF/422_rasi.pdf. Acesso em: 14 out. 2020.

Nelson, R. R., \& Rosenberg, N. (1993). National innovation systems: a comparative analysis. Oxford University Press on Demand.

Phills, J. A., Deiglmeier, K., \& Miller, D. T. (2008). Rediscovering social innovation. Stanford Social Innovation Review, 6(4), 34-43.

Saad, M., \& Zawdie, G. (2005). From technology transfer to the emergence of a triple helix culture: The experience of Algeria in innovation and technological capability development. Technology Analysis and Strategic Management, 17(1), 89-103.

Sábato, J., \& Botana, N. (1968). La Ciencia y la Tecnología en el desarrollo futuro de América Latina. Revista de la Integración. p. 15-36

Santos, F. M. (2012). A positive theory of social entrepreneurship. Journal of Business Ethics, 111(3), 335-351.

Vorley, T., \& Nelles, J. (2008). (Re) conceptualising the academy: Institutional development of and beyond the third mission. Higher Education Management and Policy, 20(3), 117.

Zhao, E. Y., Fisher, G., Lounsbury, M., \& Miller, D. (2017). Optimal distinctiveness: Broadening the interface between institutional theory and strategic management. Strategic Management Journal, 38(1), 93-113. 